\section{Medalha de Ouro Europeia em Química 2020 Atribuída ao Prof. Michele Parrinello}

A Medalha de Ouro Europeia em Química de 2020 foi atribuída ao Professor Michele Parrinello por realizações excecionais no campo da química na Europa. O Professor Parrinello será presenteado com a Medalha de Ouro durante o 8. ${ }^{\circ}$ Congresso de Química EuChemS em Lisboa, Portugal, entretanto adiado para 2022, onde deverá realizar a palestra plenária de abertura do evento.

O professor Parrinello é um físico Italiano. Atualmente, é professor na ETH de Zurique e na Università della Svizzera Italiana Lugano, na Suíça. Recebeu inúmeros prémios devido à qualidade da sua investigação. Entre eles, encontram-se o American Chemical Society Award

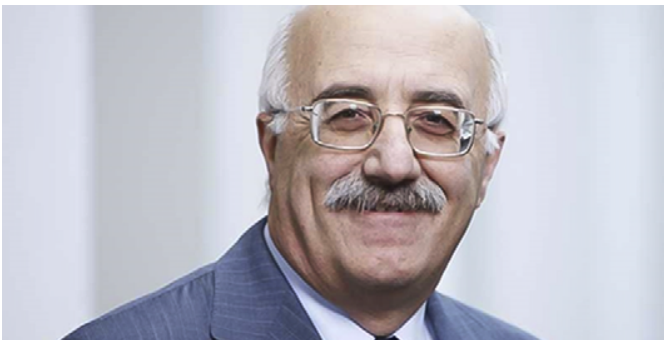

em Química Teórica (2001) e Dreyfus Prize em Chemical Sciences (2017). Já este ano, o Professor Parrinello recebeu a Medalha Benjamin Franklin (Franklin Institute) em Química. Adicionalmente, o Professor Parrinello é autor em mais de 600 publicações e membro de várias academias, incluindo a British Royal Society e a Accademia Nazionale dei Lincei.

Os seus interesses em Ciência são interdisciplinares. Juntamente com o Professor Car, ele encontra-se ainda a desenvolver e aplicar o método de dinâmica molecular Car-Parrinello. Este software de Química computacional analisa o movimento de átomos individuais. Este método tem encontrado amplas aplicações em física e química e permite que os cientistas entendam o comportamento atómico nas mais diversas aplicações.

\title{
International Dibner Award 2019 para a Exposição "Plasticidade - Uma História dos Plásticos em Portugal”
}

A exposição "Plasticidade - Uma História dos Plásticos em Portugal", recebeu em outubro de 2019, o International Dibner Award for Excellence in Museum Exhibits, galardão que tem por objetivo destacar a qualidade e a excelência de exposições patentes em museus, que apostem na interpretação e difusão da história da tecnologia, indústria e da engenharia. Parâmetros como o design, as narrativas, os objetos apresentados, bem como a pertinência dos assuntos divulgados são aspetos valorizados na atribuição deste prémio atribuído pela Society for the History of Technology (SHOT). 

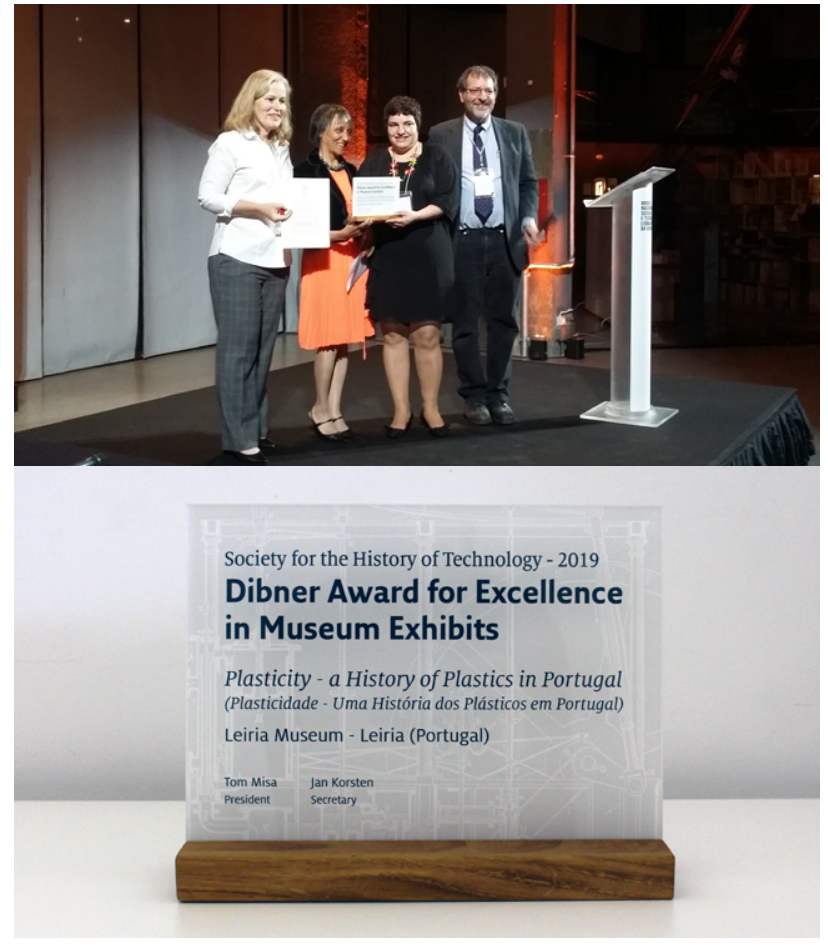

Receção do Dibner Award, Milão, outubro 2019. Crédito a Erik van der Vleuten.

Esta exposição, inaugurada a 6 de abril de 2019, resulta de uma parceria entre o Museu de Leiria e o projeto de investigação "O Triunfo da Baquelite: Contributos para uma História dos Plásticos em Portugal", desenvolvido no Centro Interuniversitário de História das Ciências e da Tecnologia da Universidade Nova de Lisboa, e coordenado por Maria Elvira Callapez, com financiamento da Fundação para a Ciência e a Tecnologia (FCT).

No âmbito deste projeto dedicado ao sector da indústria de plásticos em Portugal foi possível reunir, num curto intervalo de tempo, uma coleção de objetos muito diversificada, oriundos de museus, investigadores, colecionadores particulares, mas também de várias empresas nacionais, com particular incidência para as empresas da região de Leiria e Marinha Grande. O levantamento de objetos contou com uma campanha de angariação junto do público, tendo-se recolhido e selecionado várias centenas deles, segundo categorias, técnicas e períodos de fabrico, permitindo traçar uma cronologia dos principais marcos do desenvolvimento do sector em Portugal.

Esta coleção de plásticos incorpora histórias, tecnologias, processos, novos comportamentos e quotidianos. Especificamente, resgata todas essas vertentes para o interior da narrativa expositiva, possuindo exemplares de diversas proveniências, formatos, matérias plásticas e, cronologicamente, apresenta objetos que remontam aos anos de 1930, aquando da abertura das primeiras unidades fabris em Leiria dedicadas ao fabrico de plásticos em Portugal, passando pelos anos de 1950 a 1980, onde se desenvolveram várias unidades fabris na região de Leiria, Marinha Grande, Porto, Lisboa, Guimarães..., até à atualidade, com a produção de novos plásticos e outros sintéticos, como fibras.

Selecionar, apresentar e destacar os objetos e desenvolver uma narrativa foi o desafio do projeto museográfico, que assentou num design que funciona como elemento mediador entre o espaço e os suportes expositivos, e onde a cor e a forma são elementos de destaque da "grafia" que se desenvolve ao longo dos módulos expositivos. A representação gráfica é ela mesmo um fio condutor coerente e estrutural da exposição, presente tanto no anúncio da exposição, como nos marcadores temporais dos diferentes módulos, relacionando-se de forma direta com a cor e as formas dos objetos apresentados e, sobretudo, realçando a sua plasticidade individual ao longo dos conteúdos temáticos selecionados. 0 desenvolvimento dos módulos expositivos aposta ainda numa diversidade funcional e tipológica dos diferentes contextos sociais do objeto plástico, desde o doméstico ao industrial, ou do religioso ao infantil. A diversidade é, aliás, um ponto forte desta exposição que está associada com as tipologias de plásticos (os diferentes polímeros) e suas características químicas e físicas.

A exposição culmina com um último módulo intitulado "Arte Plástica" onde são apresentadas, entre outras, obras de arte em plástico de Nuno Sousa Vieira e outras de carácter rotativo, oriundas da coleção da Fundação Calouste Gulbenkian. Deste modo, associa-se a expressão artística com a narrativa histórica, movendo o olhar do visitante para as capacidades "plásticas" do plástico, explorando a sua plasticidade, característica que abriu o universo criativo a novas formas e composições.

A exposição conta ainda com vídeos que apresentam três aspetos diferentes em torno do uso e fabrico do plástico, nomeadamente o vídeo Le Chant de Syrene, realizado por Alain Resnais, um vídeo com relatos de antigos técnicos e operários da indústria na região de Leiria, fruto de um vasto trabalho de recolha de depoimentos desenvolvido sob a coordenação de Paula Mota Santos e a Associação "ACOA: Amigos do Parque e do Museu do Côa", e um conjunto de pequenos vídeos produzidos no âmbito de projetos de educação ambiental (alertando para as questões que envolvem a poluição dos mares e rios e as formas de tratamento dos resíduos), cedidos pelos autores ou instituições produtoras.

A exposição ficará patente até junho/julho de 2021 e abre a oportunidade para outras reflexões e 
iniciativas. O Museu de Leiria, em colaboração com o grupo de investigadores, tem desenvolvido um programa de colóquios, visitas orientadas, projetos artísticos e de animação cultural, sobre temas relacionados com a produção e transformação dos plásticos, seus usos, diversidades e plasticidades. Fica o convite.

Mais informações em visiteleiria.pt/agenda/plasticidade-uma-historia-dos-plasticos-em-portugal.
Maria da Luz Sampaio

mluzsampaio@gmail.com

Maria Elvira Callapez

mecallapez@fc.ul.pt

\section{COVID-I9 Data Portal}

\section{Comissão Europeia Lança Plataforma de Partilha \\ de Dados COVID-19 para Investigadores}

A Comissão Europeia, em conjunto com vários parceiros, lançou no dia 20 de abril de 2020 uma plataforma de dados europeia COVID-19 para permitir a rápida recolha e partilha dos dados de investigação disponíveis. A plataforma, que faz parte do plano de ação ERAvsCorona, representa mais um marco nos esforços envidados pela UE para apoiar os investigadores na Europa e em todo o mundo na luta contra o surto de coronavírus.

A nova plataforma proporcionará um ambiente europeu e mundial aberto, fiável e modulável, em que os investigadores poderão armazenar e partilhar conjuntos de dados, nomeadamente sequências de ADN, estruturas de proteínas, dados da investigação pré-clínica e de ensaios clínicos e dados epidemiológicos. Resulta de um esforço conjunto da Comissão Europeia, do Instituto Europeu de Bioinformática do Laboratório Europeu de Biologia Molecular (EMBL-EBI), da infraestrutura Elixir e do projeto COMPARE, assim como dos Estados-Membros da UE e de outros parceiros.
A partilha aberta e rápida de dados acelera consideravelmente a investigação e a descoberta, permitindo dar uma resposta eficaz à emergência do coronavírus. A plataforma de dados europeia COVID-19 é consonante com os princípios estabelecidos na declaração sobre a partilha de dados em caso de emergência de saúde pública e reforça o compromisso da Comissão de facultar acesso aberto aos dados de investigação e de promover a ciência aberta, com vista a tornar a ciência mais eficiente, fiável e capaz de responder aos desafios societais. Neste contexto, a plataforma é também um projeto-piloto prioritário, que visa realizar os objetivos da Nuvem Europeia para a Ciência Aberta (EOSC) e que tira partido das redes já estabelecidas entre o EMBL-EBI e as infraestruturas nacionais de dados de saúde pública.

Toda a informação relacionada com a COVID-19 pode ser acedida em covid19dataportal.org.

\section{Bruno Machado}

brunofm@fe.up.pt 